\title{
Validation of a protocol to evaluate maximal expiratory pressure using a pressure transducer and a signal conditioner
}

\author{
VIVIANE SOARES ${ }^{1}$, FÁBIO B. RODRIGUES ${ }^{2}$, MARCUS F. VIEIRA ${ }^{3}$ and MARIA SEBASTIANA SILVA \\ ${ }^{1}$ Programa de Pós-Graduação em Ciências da Saúde da UFG, Laboratório de Bioengenharia e Biomecânica/LaBioEng, \\ Universidade Federal de Goiás, Campus Samambaia, Caixa Postal 131, 74001-970 Goiânia, GO, Brasil \\ ${ }^{2}$ Programa de Pós-Graduação em Engenharia Elétrica e da Computação da UFG, Laboratório de Bioengenharia e \\ Biomecânica/ LaBioEng, Universidade Federal de Goiás, Campus Samambaia, Caixa Postal 131, 74001-970 Goiânia, GO, Brasil \\ ${ }^{3}$ Programa de Pós-Graduação em Ciências da Saúde da UFG e Programa de Pós-Graduação em Engenharia Elétrica e da \\ Computação da UFG, Laboratório de Bioengenharia e Biomecânica/ LaBioEng, Universidade Federal de Goiás, \\ Campus Samambaia, Caixa Postal 131, 74001-970 Goiânia, GO, Brasil \\ ${ }^{4}$ Programa de Pós-Graduação em Ciências da Saúde da UFG, Laboratório de Fisiologia, Nutrição e Saúde, \\ Universidade Federal de Goiás, Campus Samambaia, Caixa Postal 131, 74001-970 Goiânia, GO, Brasil \\ Manuscript received on February 2, 2010; accepted for publication on June 25, 2010
}

\begin{abstract}
The respiratory muscles can present fatigue and even chronic inability to generate force. So, reliable devices are necessary to their evaluation. The aim of this study is to evaluate the MEP (Maximal Expiratory Pressure) values of individuals between 20 and 25 years old and to validate a protocol using a pressure transducer and a signal conditioner comparing it with the digital manometer. We evaluated the MEP of 10 participants. They remained seated and made six respiratory maneuvers from Total Lung Capacity (TLC) to Residual Volume (RV). The results in the study showed no statistically significant differences when compared to values reported in the literature, and that the pressure transducer provides reliable values for MEP.
\end{abstract}

Key words: Evaluation and validation, Respiratory muscle strength, Maximal Expiratory Pressure.

\section{INTRODUCTION}

The muscle strength can both reflect the health state and predict the performance for certain arrangements of sports (Schneider et al. 2004). Therefore, its evaluation is important.

The contraction of respiratory muscles can be controlled automatically or voluntarily conducted by the medula oblongata respiratory center. However, the respiratory muscles can present fatigue and even chronic desability to generate force. Therefore, their evaluation is also necessary. It can be performed by a variety of instruments: the digital manometer (use of static MIP - Maximal Inspiratory Pressure and MEP - Maximal

Correspondence to: Marcus Fraga Vieira E-mail: marcus.fraga.vieira@gmail.com
Expiratory Pressure) and the Maximal Voluntary Ventilation (MVV), which are the most common (Neder et al. 1999).

Since the $60^{\prime} \mathrm{s}$ and $70^{\prime} \mathrm{s}$, the MIP and MEP have been considered a simple, practical and accurate method in assessing the strength of respiratory muscles in both healthy individuals and patients from different clinicals. The measurement of maximal respiratory pressure depends on the conduction of specific exercises and the individuals cooperation to perform maximal respiratory efforts (Costa et al. 2003).

Maximal respiratory pressures are simple to obtain and provide useful information in clinical practice and research with patients with abnormal respiratory muscle strength (Bartolome 1989). 
The first aim of this study has been to assess the maximal expiratory pressure in individuals between 20 and 25 years old through the digital manometer, using as reference the standard values found by Neder et al. (1999). The second has been to validate a method using a pressure transducer and a signal conditioner to assess respiratory muscle strength by comparing it with the digital manometer. The two methods will be compared in order to provide another device in the assessment of respiratory muscle strength. Still, we don't prove the superiority of one method over another, but confirm the use of signal conditioning and the pressure transducer to evaluate MEP.

\section{MATERIALS AND METHODS}

Ten male healthy individuals, between 20 and 25 years old, have taken part in the study. Individuals with report of pulmonary disease and smokers have being excluded. All participants signed a consent approved by the Ethics Committee in Research of Federal University of Goiás.

A portable digital Manometer MVD300 (Globalmed) has been used with $1 \mathrm{cmH}_{2} \mathrm{O}$ of resolution, 480 $\mathrm{cmH}_{2} \mathrm{O}$ full scale, a atmospheric pressure transducer (EMG System of Brazil) and a signal conditioner with 16 channels (EMG System of Brazil): A/D conversion board with 16 bits of resolution; work range of $\pm 10 \mathrm{~V}$; maximal sampling frequency of $4.8 \mathrm{kHz}$; amplification of 100 times; and band-pass filter with cut-off frequencies between 10 and $500 \mathrm{~Hz}$ (Fig. 1). These cut-off frequencies are typical of the equipment (EMG System of Brazil), which can also be employed in surface EMG.

The instruments have been calibrated by linear regression (Fig. 2), from seven measurements coupling the pressure transducer to the input of the digital manometer, in order to assess the MEP through an unidirectional valve (Hans-Rudolph valve).

The individuals have seated comfortably in a fixed chair wearing nose clips and with a rigid plastic flanged mouthpiece in place. They have performed six maximal voluntary expirations (three maneuvers in digital manometer and three in pressure transducer) from Total Lung Capacity (TLC) to Residual Volume (RV). The maneuvers have been repeated with an interval of 90 seconds.
The signals have been conditioned in MatLab (C1994-2009 The MathWorks, Inc.) to eliminate noise and artifacts of high frequency using the low pass fourth order Butterworth filter with cut-off frequency of $5 \mathrm{~Hz}$. The mean value and standard deviation of MEP have been calculated.

In order to compare the MEP measurements obtained by digital manometer and the pressure transducer, the student $t$ test for dependent samples has been performed, whereas the Pearson correlation test has been used to determine a correlation between these methods. The level of significance adopted was $p<0.05$.

\section{RESULTS}

In the present study, the mean values found to digital manometer and pressure transducer were $135.8 \pm 25$ $\mathrm{cmH}_{2} \mathrm{O}$ and $136.8 \pm 15.4 \mathrm{cmH}_{2} \mathrm{O}$, respectively. Neder et al. (1999) found average values of $143.3 \pm 11 \mathrm{cmH}_{2} \mathrm{O}$ for individuals of the same age. There were no statistically significant differences between the MEP values obtained by the digital manometer and by the pressure transducer. All parameters showed high agreement and correlation coefficient $(0.9740)$.

\section{DISCUSSION}

The expiratory muscles are important rotators and trunk flexors. Their contractions move the abdominal wall inwards, increasing the abdominal pressure (Slutzvy 1996). So, as a consequence, the diaphragm moves cranially inward the thoracic cavity, pulling the lowers ribs caudally in order to deflate the rib cage (Ratnovsky et al. 2008). Thus, the expiratory muscles are powerful in the activities of cough and forced expiration.

Indeed, the expiratory muscles can be important in respiration at rest. These muscles can stimulate the inspiratory function of the diaphragm, mainly in the sitting position and standing positions. So, the persistent contraction of the abdominal muscles in a standing position increases the ability of the diaphragm to generate and increase lung volume (Slutzvy 1996).

Therefore, the reduction in the generation of force by expiratory muscles can endanger all the biomechanics of the thorax and the volumes and lung capacities.

Arora and Rochester (1982) showed that mal- 


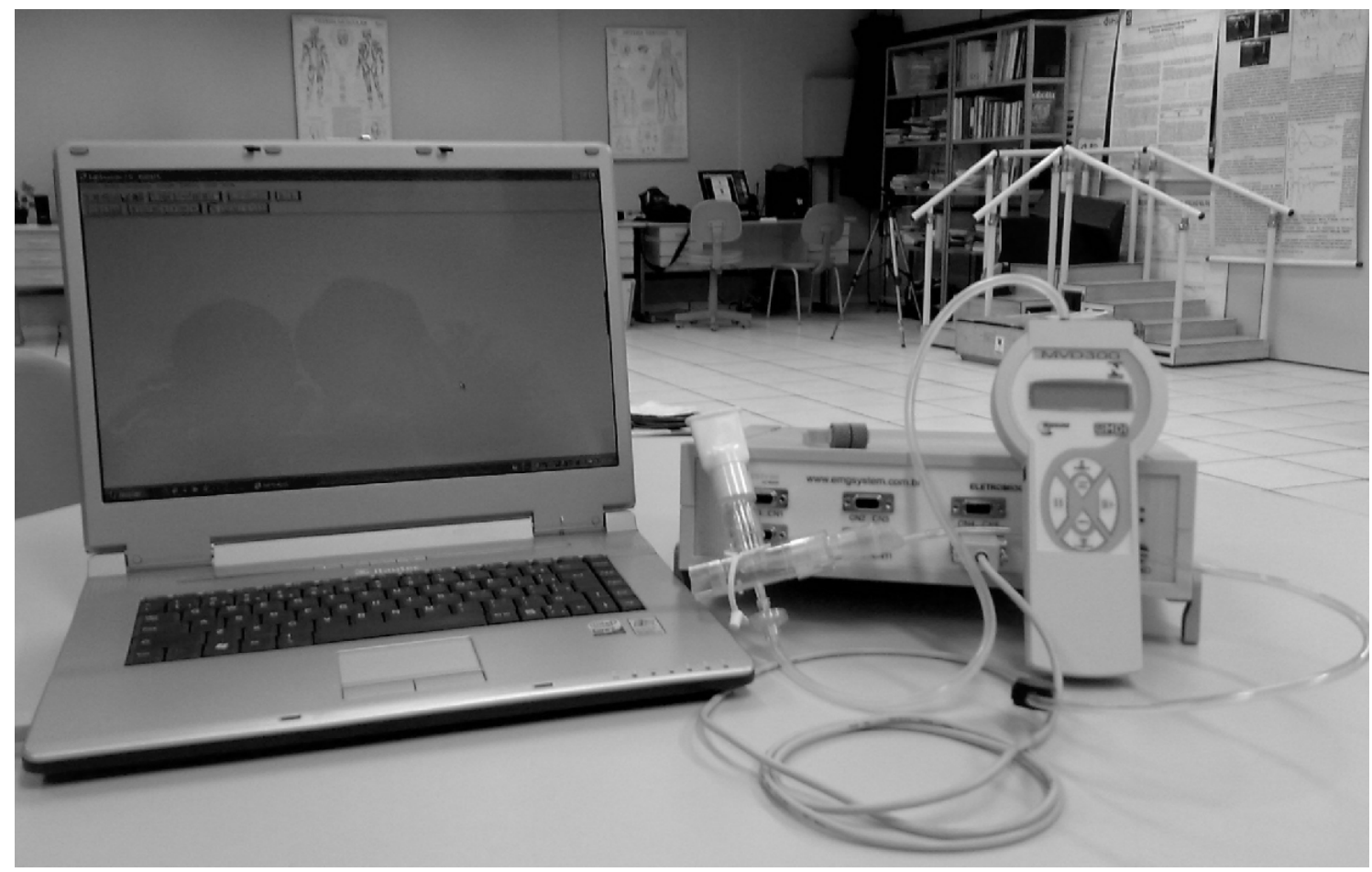

Fig. 1 - Computer, signal conditioner and portable digital monometer.

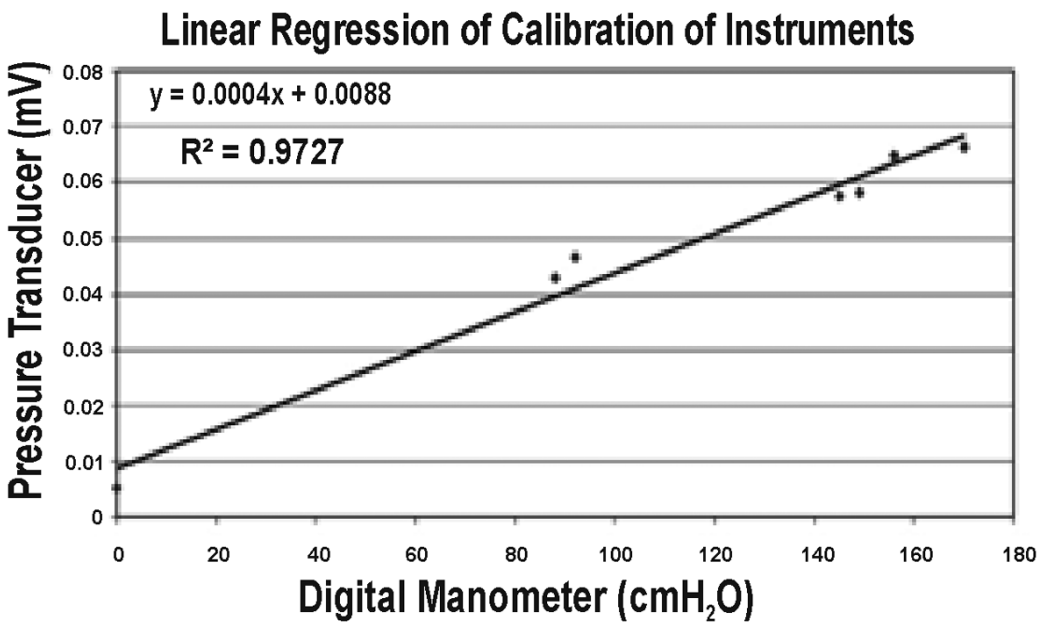

Fig. 2 - Linear regression for calibrating the instruments.

nutrition affects the respiratory muscles. According to these authors, changes in muscle mass influence muscle strength and endurance.

$\mathrm{Ng}$ and Stokes (1991) evaluated MIP and MEP in the sitting position and at $40^{\circ}$ of trunk inclination in normal, non-smoking individuals and found no significant differences in the values of maximal pressures.
Neder et al. (1999) have established Brazilian population reference values for MIP, MEP and MVV in groups between 20 and 80 years old. They have found that, in some groups, the male expiratory pressure is greater than the inspiratory pressure. This result reflects a greater strength of the abdominal muscles.

In our study, there were no statistically significant 


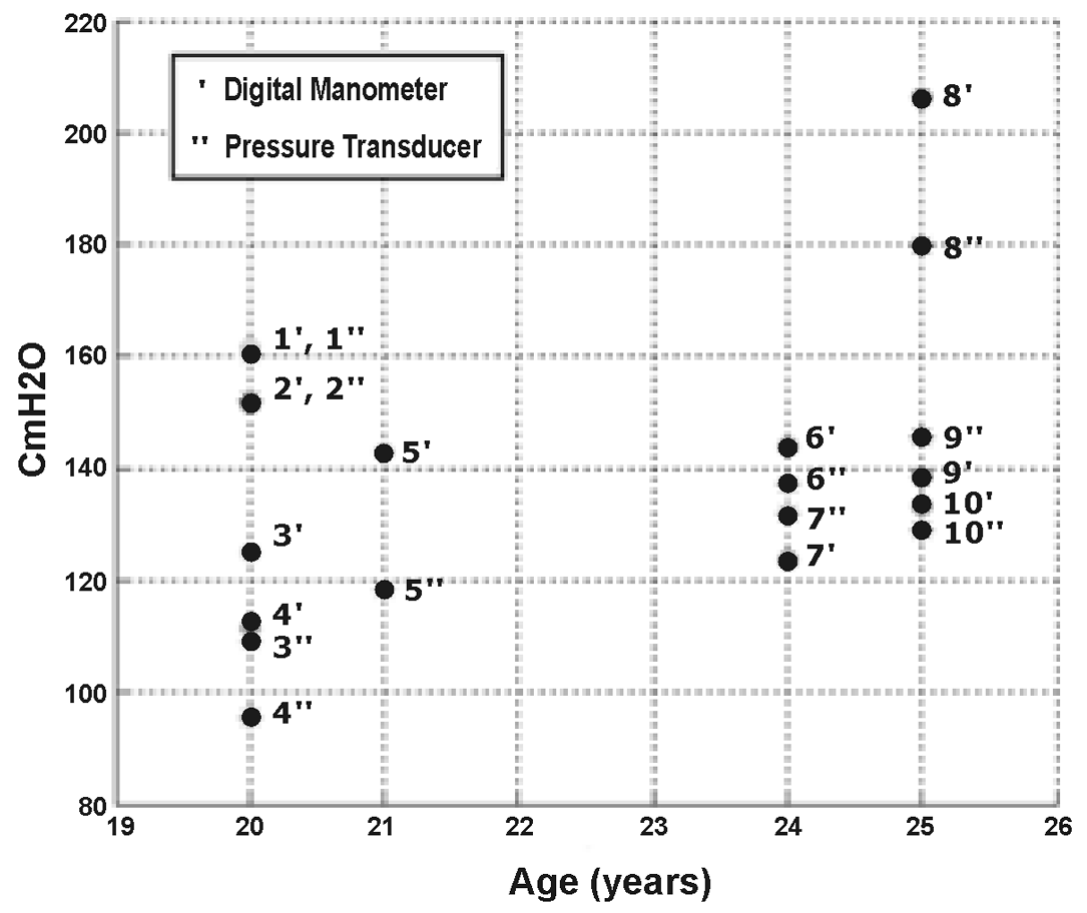

Fig. 3 - Comparison of digital manometer and pressure transducer. The individuals are represented by the same colors: * - digital manometer, o - pressure transducer. The closer the symbols, the smaller the differences among the results.

differences in MEP using a digital manometer and a pressure transducer (Fig. 3). Indeed, the results were similar to those found by Neder et al. (1999), although the age of the individuals was not exactly the same. It was not possible in this study to check the age influences in the peak of strength of respiratory muscles as described by Black and Hyatt (1969).

The study has also showed that the pressure transducer coupled to a signal conditioner provides reliable values of MEP, which, in turn, reflects the strength of the muscles involved in active expiration in healthy individuals.

\section{CONCLUSION}

In this study, statistically significant differences were not found for values of MEP using a digital manometer and a pressure transducer, showing that the pressure transducer provides reliable values for MEP.

\section{ACKNOWLEDGMENTS}

Coordenação de Aperfeiçoamento de Pessoal de Nível Ensino Superior (CAPES), Conselho Nacional de De- senvolvimento Científico e Tecnológico (CNPq) and Fundação de Amparo à Pesquisa do Estado de Goiás (FAPEG) for financial support.

\section{RESUMO}

Os músculos respiratórios podem apresentar fadiga e até mesmo a incapacidade crônica na geração de força, sendo necessários dispositivos confiáveis para sua avaliação. O objetivo deste estudo foi avaliar a pressão expiratória máxima ( $\left.\mathrm{Pe}_{\text {Máx }}\right)$ de indivíduos entre 20 e 25 anos e validar um protocolo que utiliza um transdutor de pressão e um condicionador de sinais comparando-o com a manovacuometria. Foram avaliadas a $\mathrm{Pe}_{\text {Máx }}$ de 10 participantes. Estes permaneceram sentados e realizaram seis manobras respiratórias a partir da capacidade pulmonar total (CPT) até o volume residual (VR). Os resultados do estudo não apresentaram diferenças estatisticamente significativas quando comparados com os valores de normalidade descritos na literatura e mostraram que o transdutor de pressão fornece valores confiáveis para $\mathrm{Pe}_{\text {máx }}$.

Palavras-chave: Avaliação e validação, Força muscular respiratória, Pressão Expiratória máxima. 


\section{REFERENCES}

ARORA NS AND ROCHESTER DF. 1982. Respiratory muscle strength and maximal voluntary ventilation in under nourished patients. Am Rev Respir Dis 126: 2-8.

Bartolome RC. 1989. Clinical and Physiologic Evaluation of Respiratory Muscle Function. Clin Chest Med 10: 199-214.

BLACK LF AND HYATT RE. 1999. Maximal respiratory pressures: normal values and relationship to age and sex. Am Rev Respir Dis 99: 696-702.

Costa D, SAmpaio LMM, LoREnZzo VAP, JAMANi M AND DAMASo AR. 2003. Avaliação da força muscular respiratória e amplitudes torácicas e abdominais após a RFR em indivíduos obesos. Rev. Latino- Am Enfermagem 11: 156-160.

Neder JA, Adreoni S, Lerario MC And Nery LE. 1999. Reference values for lung function tests II. Maximal respiratory pressures and voluntary ventilation. Rev Assoc Med Bras 32: 719-727.
NG GY AND Stokes MJ. 1991. Maximal inspiratory and expiratory mouth pressures in sitting an half - lying positions in normal subjects. Respiratory Medicine 85: 209 211.

RATNOVSKY A, ELAD D AND HALPERN P. 2008. Mechanics of respiratory muscles. Respiratory Physiology and Neurobiology 163: 82-89.

Scheider P, Benetti G AND Meyer F. 2004. Força muscular de atletas de voleibol de 9 a 18 anos através da dinamometria computadorizada. Rev Bras Med Esporte 10: $85-91$.

SLUTZVy LC. 1996. Músculos Respiratórios: Uma Breve Revisão. Revista Sul - Americana de Fisioterapia Respiratória 1: 17-25. 